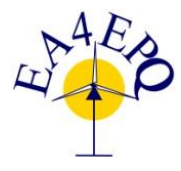

International Conference on Renewable Energies and Power Quality (ICREPQ'19)

Tenerife (Spain), $10^{\text {th }}$ to $12^{\text {th }}$ April, 2019

Renewable Energy and OPourer Qualily. Fournal (RE\&PQJ)

ISSN 2172-038 X, No.17. July 2019

\title{
Is Objection to Wind Energy Justified?
}

\author{
M. Alrefai ${ }^{1}$ and A. Pourmovahed ${ }^{2}$ \\ ${ }^{1}$ Mechanical Engineering Graduate Student \\ Phone number: 001810447 5820, e-mail: eng.malrefai@gmail.com \\ ${ }^{2}$ Professor of Mechanical Engineering \\ Phone number: 001810 762-9758, e-mail: apourmov@ kettering.edu \\ Kettering University \\ Flint, Michigan, U.S.A. 48504
}

\begin{abstract}
Wind power has been used by humans for over 7000 years. The first known example of wind power use is most likely the utilization of sailboats used by Phoenicians and Egyptians. Windmills have been used on a small scale for many centuries primarily for the purpose of milling grains and pumping water. The use of wind turbines to produce large amounts of electricity has occurred in recent times. The most powerful wind turbine today is an 8-MW turbine for offshore use. According to the U.S Energy Information Administration (EIA), as of March 2017, wind and solar power were contributing about $10 \%$ of the electricity generated in the United States. Resistance to change is a part of human nature and, as expected, has prompted some individuals and groups to oppose the development of wind power in their communities. The "Not In My Back Yard" (NIMBY) phenomenon is well known and has been cited as the force against many new developments in numerous communities around the world. This paper reports the results of a study investigating common reasons cited for objections to wind power installations. Under some circumstances, some of the claims against wind power may be justifiable while in other cases the objections appear to be completely baseless.
\end{abstract}

\section{Key words}

Wind Power, Renewable Energy, Objection to Wind Power, Wind Power Disadvantages

\section{Introduction}

Humans have been utilizing wind energy for thousands of years, beginning with harnessing wind energy for powering ships and boats, and recently -with significant technology advancements- to generate electricity.
Ancient Egyptians used wind energy to propel their boats along the Nile River as early as 5000 B.C. Persians are thought to be the first to build and operate windmills around 500 A.D. These windmills were either connected to a grindstone in order to grind grains or connected to a water pump. During the $11^{\text {th }}$ century, windmills and wind-pumps were developed and used widely in the Middle East and around the world to facilitate food processing and for pumping water. In the 1800's, steel blades were used in windmills in The United States. The blades would fold up in high wind conditions in order to save the blades from being damaged. These later evolved into wind turbines that can harness the energy from the wind and turn it into electrical energy.

The terms "windmill" and "wind turbine" are sometimes used interchangeably even though they are used for different purposes. Windmills convert wind power into mechanical power used to operate a pump or a grinding wheel while wind turbines are utilized to convert wind power into electricity through an electric generator. Wind turbines are generally classified as belonging to two main categories: vertical and horizontal axis. Horizontal axis turbines are more popular. Their blades rotate about an axis parallel to the ground. A vertical axis turbine rotates around an axis perpendicular to the ground. Horizontal axis turbines typically have three blades and usually face the wind. According to Betz's Law the maximum energy that can be extracted by a wind turbine is $59.3 \%$ of the kinetic energy available in the wind. Actual efficiencies are much less but can be improved by techniques such as adding a wind lens around the propeller [1]. 
With massive increases in demand for electricity and the need for more sources of energy in recent decades, wind power was been proven to be a viable and sustainable source of clean energy. It has a promising future as it reduces dependency on fossil fuels. Considering the environmental and social impacts of conventional energy technologies and sources, and the fact that energy independence is often a national security issue, it is easy to see why wind energy has a special place in the basket of energy resources as its source is readily available in many areas of the world; it is sustainable and essentially harmless.

Not unlike other sources of energy, there are a variety of advantages and disadvantages associated with wind energy. Perceptions and acceptance of wind energy varies across the world. It is often based on local culture, level of education and how a community perceives to be affected by the presence of wind turbines or wind farms.

In July of 2008, the U.S. Department of Energy released a report [2] stating that by the year 2030, 20\% of the U.S. energy will come from wind; $35 \%$ by 2050.

\section{Global Energy Demand and the Wind Energy Contribution}

Figure 1 shows the global energy consumption by source for a 50-year period. Sadly, a big portion of the energy used comes from fossil fuels. This negatively impacts human health and the environment due to harmful emissions of many gases including carbon dioxide, which has been blamed as a primary contributor to man-made global warming and climate change.

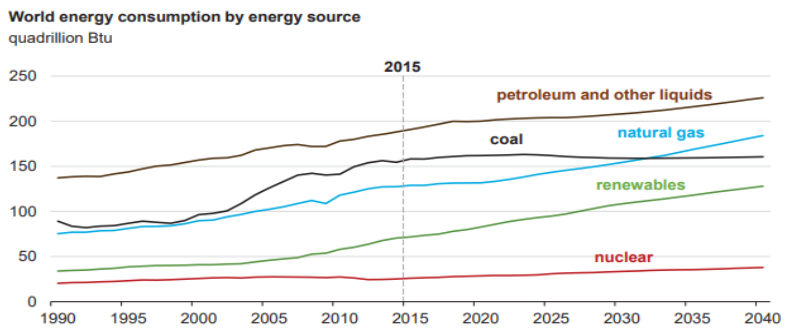

Fig. 1. World energy consumption by source [3]

A rapid rise in global energy demand is clearly seen in Fig. 2 indicating an $86 \%$ rise in global demand in just 30 years.

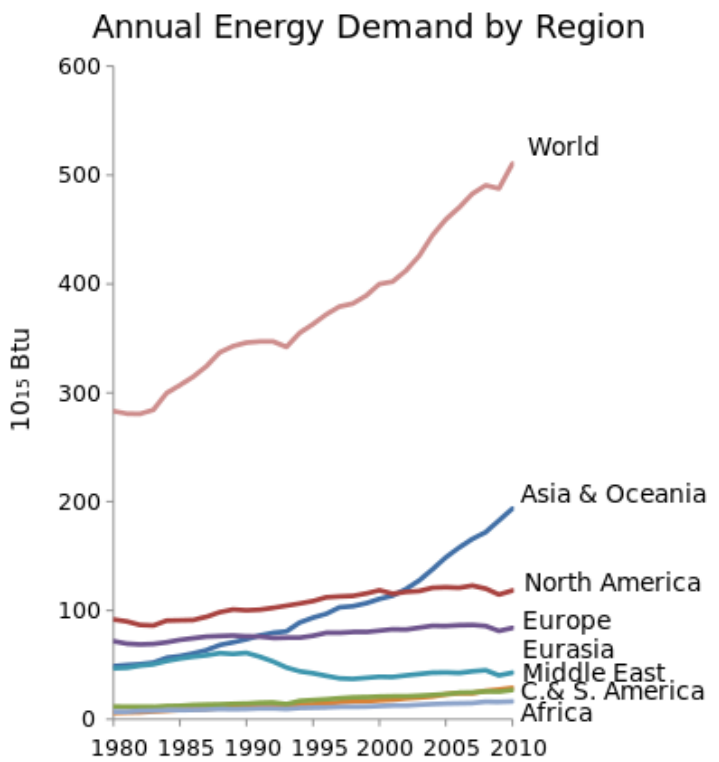

Fig. 2. World primary energy consumption in quadrillion Btu from 1980 to 2010 (U.S. Energy Information Administration)

To combat $\mathrm{CO}_{2}$ emissions (climate change abatement), reduce emissions harmeful to human health and approach energy independence, many countries around the world have embraced wind energy. Global growth in wind energy utilization has been very impressive (Fig. 3). Many advantages of wind energy - including lack of dependence on fossil fuels, emissions-free operation, and sustainability - have made it one of the fastest growing energy sources around the world. The only emissions attributed to wind energy occur during the construction and maintenance stages.

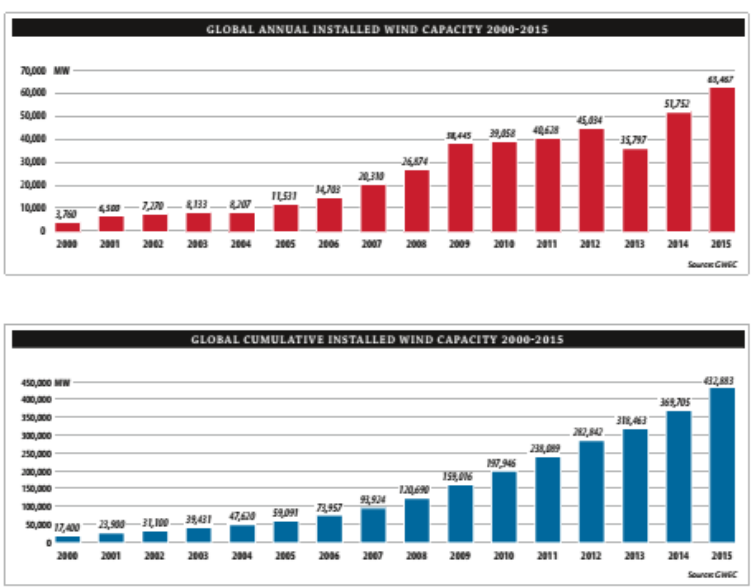

Fig. 3. Annual and Cumulative Installed Wind Capacity [4]

Conventional (fossil fuel) power plants use a tremendous amount of water for cooling the condenser as well as supplying make up water to cooling towers. Warm water from the cooling system is often returned 
to a lake or river affecting marine life. In contrast, wind farms consume no water.

Not unlike other sources of energy, wind energy faces some challenges. Real and perceived negative impacts have resulted in some opposition from local communities who are against its development and spread. Not all cited objections can be justified.

\section{Alleged Problems and Objections}

Any large industrial installation can have an impact on surrounding life. This may lead to some local opposition to the project. As shown in Fig. 4, opposition to wind energy is much less than that for fossil fuel and nuclear energy installations. In this study, some of the reasons behind opposition to wind energy will be highlighted.

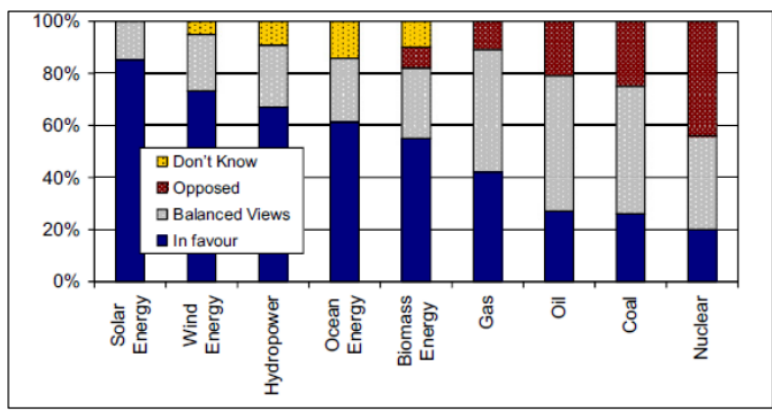

Fig. 4. Social acceptance of different types of electricity generation technologies according to the European Commission, 2007

\subsection{Noise and Effect on Human Health}

Wind turbines, having moving blades, gears and other rotating components, will generate some noise. Depending on how far people live from a wind turbine, the noise may be objectionable. It has been claimed by some that wind turbine noise has a direct impact on their quality of life, causing problems such as anxiety and sleep deprivation. As an example, according to the Irish Examiner [5], a group of seven Irish families sued a wind farm operator claiming that the large wind turbines adversely affected their health. According to [5] the wind farm operator admitted liability over noise pollution.

Fig. 5 shows the level of noise produced by a typical wind turbine compared to common household appliances. At a distance of $100 \mathrm{~m}$ from the wind turbine, the noise level is about $50 \mathrm{~dB}$, similar to that emitted by a midsize window air conditioner or a car traveling at $60 \mathrm{~km} / \mathrm{h}$ at the same distance. Wind turbines are rarely placed within $300 \mathrm{~m}$ from the closest home.

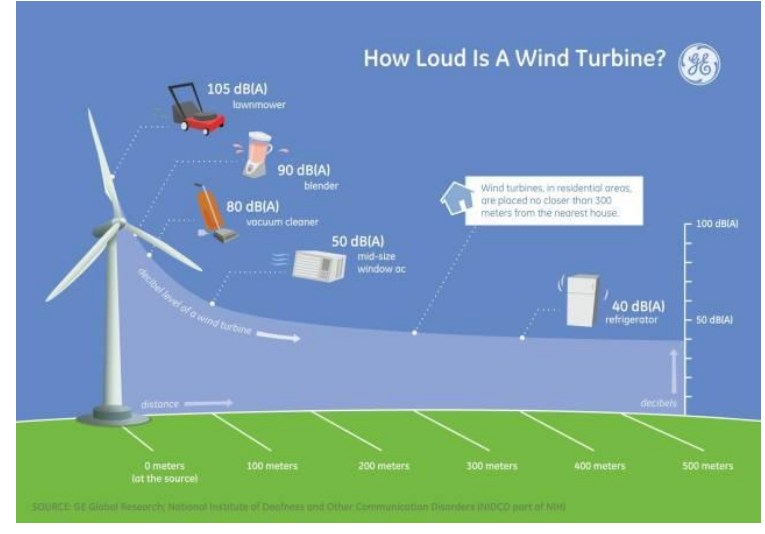

Fig. 5. Noise produced by wind turbines compared to household appliances [6]

In some studies, persons exposed to wind turbine noise have blamed it for sleep-related problems, tinnitus (the perception of noise, ringing of the ears), headaches and vertigo. Relations between exposure to wind turbine noise and real or perceived health effects have been reviewed extensively and systematically by J. H. Schmidt and M. Klokker [7]. This study concludes that while "Exposure to wind turbines does seem to increase the risk of annoyance and self-reported sleep disturbance in a dose-response relationship", "of the many other claimed health effects of wind turbine noise exposure reported in the literature, however, no conclusive evidence could be found."

\subsection{Aesthetics/Not in My Backyard "NIMBY" Syndrome}

Despite many economical and environmental advantages that a wind energy installation offers, not all people like its appearance, particularly if a wind farm with a large number of wind turbines is involved. The turbine or multiple turbines in a wind farm can potentially block people's view of a beautiful ocean, lake or a forest. Many of these people believe in wind energy as a valuable source of energy but reject it egocentrically. Furthermore, people in a rural area are concerned that having these turbines close to their neighborhood will diminish their property values.

Some people also complain that these big scale blades moving close to them will flicker the shadow and cause the sun's reflection at different times of the day (Fig. $6)$. They are not happy with the reflections or the redlight blinker on top of the turbine all day and all night. 


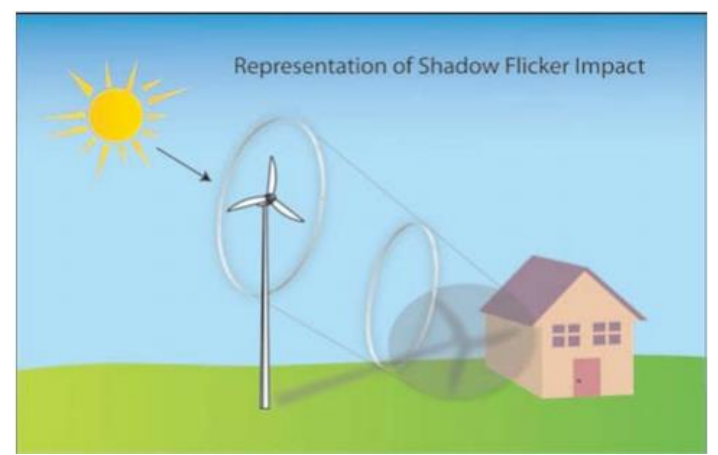

Fig. 6. Turbine flickers shadow on the building during a certain periods of day (American Wind Energy Assoc)

In an article by Peter Allen and published in Daily Mail in November 2013 [8], he writes about a legal claim opened by a French couple after the view from their dream home was obstructed by a wind farm. According to this article, "Erik Wallecan and his wife Ingrid have won a landmark legal battle to have 10 wind turbines taken down because they spoil the view from their dream home in France. The company was ordered to pay the Wallecans the equivalent of $£ 31,500$ in damages and to remove the wind farm within four months or face a fine of $£ 450$ per day per turbine”.

\subsection{Blade Icing}

Wind turbine icing has been a concern in many areas that experience very cold weather or are at a high altitude. When formed on the blades of a wind turbine, ice can present a serious challenge (Fig. 7). It may be thrown and scattered on the surrounding areas while the wind turbine rotor is spinning in cold climates. Some wind turbines are equipped with a safety system that stops the rotor from spinning when a significant amount of ice is detected on the blades. Wind turbine Anti-icing and De-icing techniques have been discussed by Parent and Ilinca [9].

Some effective methods for wind turbine icing prevention include heating of blades and passive hydrophobic coating.

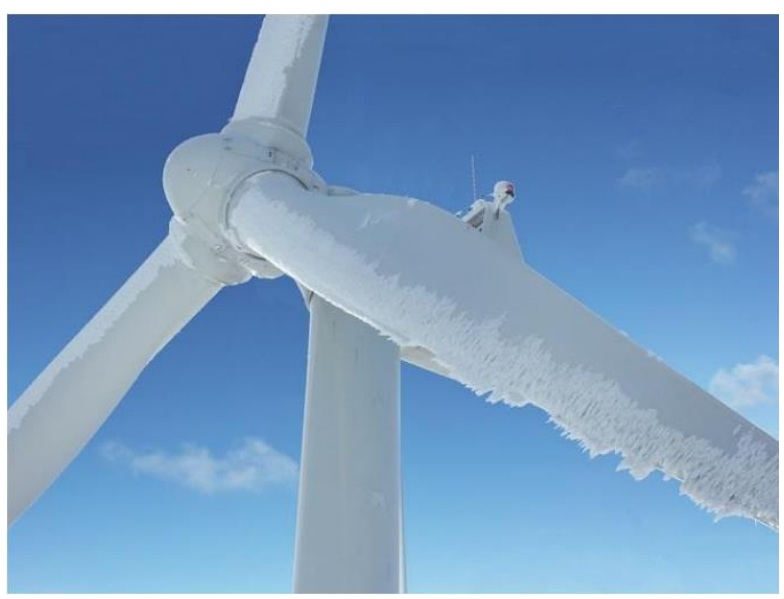

Fig. 7. Ice on a wind turbine blade [10]

\subsection{Impact on Wildlife}

One of the concerns raised against wind power is its risk to wildlife. The issues cited range from disturbing the habitat of local species during the construction phase to birds killed as they fly into the tower or are struck by moving blades. This is particularly concerning during the birds' migration season (Fig. 8). The birds include endangered species such as bats and eagles. As an example, in 2015-2016 a southern Arizona wind farm was investigated criminally for alleged death of endangered bats and federally protected golden eagles [11].

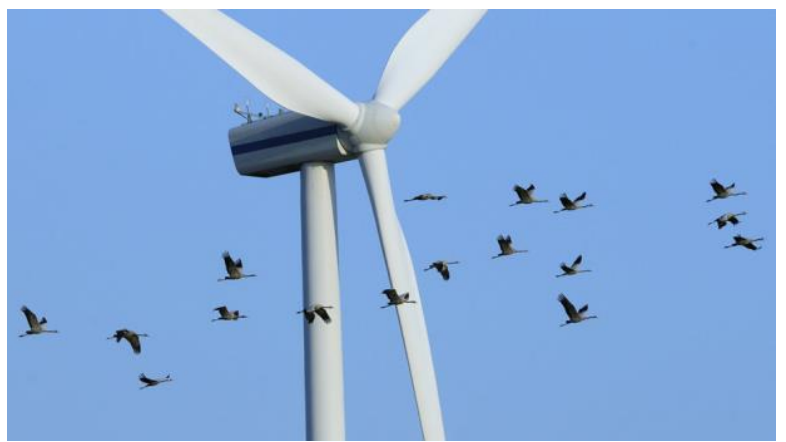

Fig. 8. Birds passing by a stationary wind turbine [12]

In a 2007 study by the National Research Council and a 2011 study by Kaldellis and Zafirakis [13] it is claimed that "the numbers of bird and bat deaths as a result of wind turbine structures is much smaller compared to mortalities due to collisions with buildings, towers, pesticides, communication towers, vehicles, power lines and other manmade installations" (Fig. 9). 


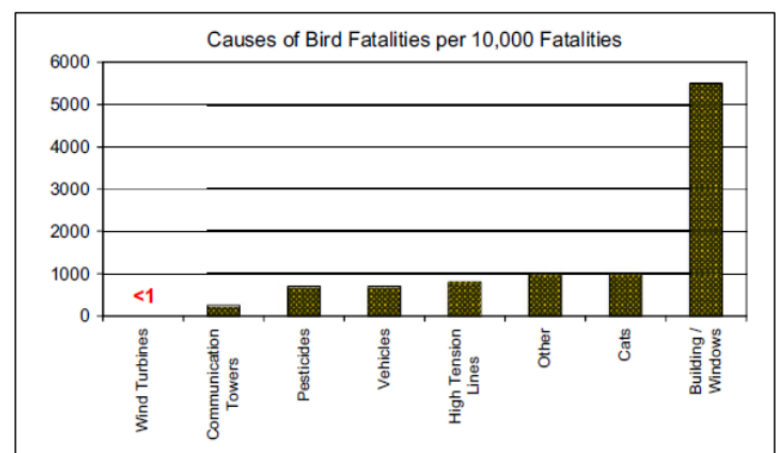

Fig. 9. Causes of bird fatalities according to [13]

One should not neglect the long term benefits of wind turbines to wildlife. Being a green source of energy, they help reduce carbon dioxide emissions and other forms of pollution and, as such, abate climate change. This in turn has many benefits to humans and wildlife. To minimize their impact on birds and other wildlife, location of major wind turbine installations must be carefully selected.

\subsection{Oil Leaks-Pollution}

Wind turbines can be enormous in size (Fig. 10) and contain many components including gears and, in most case, a cooling system. They need a lubrication system to maintain this machine in a good working condition.

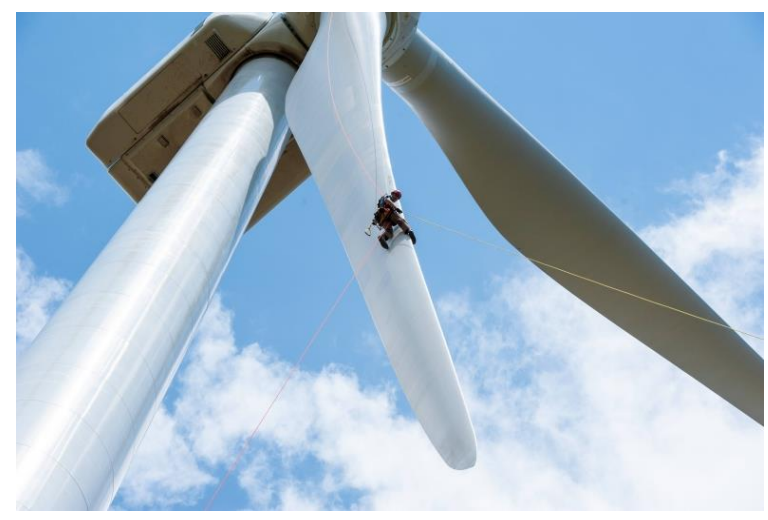

Fig. 10. The average rotor diameter of turbines installed in 2015 grew to 102 meters [14].

Oil leaks from a wind turbine nacelle can be a major problem. The fluid can run down the tower (Fig. 11) and scatter around the base of the wind turbine, affect the soil and plants around the turbine and possibly contaminate the drinking water. The contamination caused by an oil leak can have an impact on people living close to the turbines or any wild or farm animals crossing the affected area. Similar problems can be caused by offshore turbines, possibly affecting marine life.
It should be noted that a personal vehicle or any type of farm equipment could have a similar polluting impact during an accident or even during normal operation and maintenance. A robust wind turbine system design and professional maintenance can greatly reduce the risk of oil leaks from wind turbines.

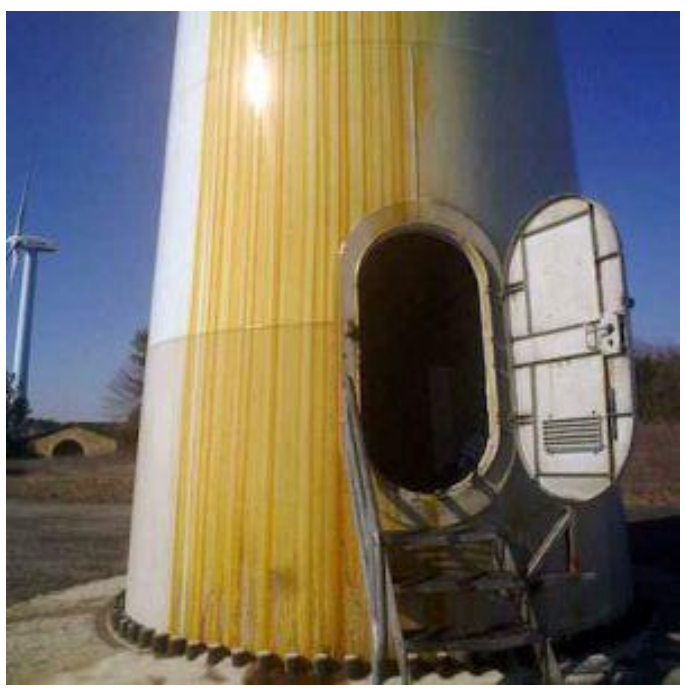

Fig. 11. Oil leak along a wind turbine tower in the Sierra de El Perdón [15]

\section{Future of U.S. Wind Energy}

The growth of wind power utilization in the United States during the last two decades has been immense. New installations in many states, particularly Texas, have added capacity on a steady pace. According to [16] the State of Texas leads the nation with 23,262 MW of installed capacity (14.8\% of in-State energy production), more than 3 times the installed capacity of any other U.S. state. This is partly because of the high wind power classification of Texas as part of the "onshore wind corridor".

All facts and figures point to a bright future for the wind energy industry. Although some communities still have their concerns about possible impact of wind farms on their immediate surroundings and their quality of life, few argue that fossil fuels offer a better choice in the long run. One important factor is the "climate change" factor taken more seriously by most communities around the world and blamed partly on the continued use of fossil fuels. It should be pointed out that a recent study by Miller and Keith [17] claims that meeting today's $0.5 \mathrm{TW}_{\mathrm{e}}$ US electricity demand using only wind power may increase the Continental United States surface temperatures by $0.24{ }^{\circ} \mathrm{C}$. This warming is caused, in part, by turbines redistributing heat by mixing the near-ground air, particularly at night. 
Recent technological advances in the wind energy industry along with many countries' desire to reach energy independence-crucial to their national securitywill open the door for more utilization and growth of this industry.

\section{Conclusions}

It is quite clear that wind power has a promising future globally. It offers many advantages such as sustainability of its energy source and no harmful emissions (unless you count the emissions during its manufacture and installation). By not emitting $\mathrm{CO}_{2}$, it cannot be blamed for contributing directly to global warming and climate change. With mass production and wide use of wind turbines, large amounts of power can be produced at a cost comparable to current conventional methods.

Being a relatively new source of power on a large scale, wind energy is still an industry largely unknown to the general public. It takes time before it is perceived by the public as a safe, viable, alternative source of power. Large wind farms are generally perceived to result in a drop in property values hence they are opposed by some local communities. Blocking a good view is often cited as another reason to oppose wind turbines.

Many factors need to be considered in order to reduce any possible real or perceived concern about the impact of a new wind project. Overcoming the objections requires a lot of research and data analysis while paying attention to the location, weather, wildlife, etc.

To put safety concerns in perspective, it should be noted that wind energy is much safer than most other forms of energy we use every day. All forms of energy when harvested, transported or used pose a risk. Examples are nuclear power (1986 Chernobyl disaster, 2011 Fukushima disaster), hydropower (2009 Sayano Shushenskaya Dam catastrophic accident), petroleum (2010 Deepwater Horizon, many major oil spills from tankers) as well as numerous coal mine accidents around the world. It is the authors' opinion that under some circumstances, a few of the claims against wind power may be justifiable while in other cases the objections are completely baseless.

\section{Acknowledgement}

The authors are grateful to an unknown reviewer for her/his many constructive remarks resulting in a much improved article.

\section{References}

[1] A. Rapin, S. Commet, A. Monroe, J. Hendley, and A. Pourmovahed, "Design and Testing of Horizontal Axis Wind Turbine Blades and Components to Increase Efficiency," $5^{\text {th }}$ International Youth Conference on Energy (IYCE 2015), Pisa, Italy, May, 2015.

[2] 20\% Wind Energy by 2030: Increasing Wind Energy's Contribution to U.S. Electricity Supply. https://www.energy.gov/eere/wind/20-wind-energy2030-increasing-wind-energys-contribution-uselectricity-supply

[3] https://www.eia.gov/outlooks/ieo/pdf/0484(2017).pdf

[4] Global Wind Report, Annual Market Update 2015. http://www.gwec.net/wp-content/uploads/vip/GWECGlobal-Wind-2015-Report_April-2016_22_04.pdf

[5] Irish Examiner, 14 June, 2017. https://www.irishexaminer.com/ireland/wind-farmbeing-sued-by-families-admits-its-liability-442172.html

[6] T. Kellner, "How loud is a Wind Turbine?," 2014. https://www.ge.com/reports/post/92442325225/howloud-is-a-wind-turbine/

[7] J. H. Schmidt and M. Klokker, "Health Effects Related to Wind Turbine Noise Exposure: A Systematic Review", PLoS One. 2014; 9(12): e114183, Published online 2014 Dec 4. doi: 10.1371/journal.pone.0114183

[8] P. Allen, "Couple win landmark battle to have 10 wind turbines taken down because they spoil the view from their dream home in France," Daily Mail, 2013. https://www.dailymail.co.uk/news/article2490820/Couple-win-landmark-battle-10-wind-turbinestaken-spoil-view-dream-home-France.html

[9] O. Parent and A. Ilinca, "Anti-icing and de-icing techniques for wind turbines: Critical review", https://doi.org/10.1016/j.coldregions.2010.01.005

[10] https://stopthesethings.files.wordpress.com/2018/03/icecovered-blade.jpg

[11] National Wind Watch - Feds investigate Arizona wind farm for killing protected species. https://www.wind-watch.org/news/2018/03/21/fedsinvestigate-arizona-wind-farm-for-killing-protectedspecies/

[12] J. Shields, "What Wind Power Critics Who Cry 'Bird' Get Wrong," 2017. https://science.howstuffworks.com/environmental/energ y/wind-power-turbines-birds-danger.htm

[13] J. Kaldellis and D. Zafirakis, "The wind energy (r)evolution: A short review of a long history," https://www.sciencedirect.com/science/article/pii/S0960 148111000085

[14] https://energy.gov/articles/top-10-things-you-didntknow-about-wind-power

[15] https://wcfn.org/2014/07/02/wind-turbines-contaminate/

[16] American Wind Energy Association, Fact Sheet. https://www.awea.org/resources/fact-sheets/state-factssheets

[17] L. Miller and D. Keith. 10/4/2018. "Climatic Impacts of Wind Power" Joule, 2. https://keith.seas.harvard.edu/publications/climaticimpacts-wind-power 